\section{Tragic dilemmas}

James M. Jasper

The Monkey Wars. By Deborah Blum. Oxford University Press: 1994. Pp. 294. $\$ 25$.

No matter how familiar they have become, the cognitive capacities of nonhuman primates still impress us. Chimpanzees can learn more than a hundred words in sign language or keyboard symbols, and they can piece them together in new ways. Lacking a symbol for cucumber, one asks for a "green banana". Another, introduced to fellow chimps for the first time, is unimpressed, dismissing them as "bugs... black bugs". Those who have mastered sign language use it to talk to themselves when alone, to other chimps, even to their inanimate toys. They can make the remarkable leap of classifying words. Two of them, when asked to group 17 nouns as either tools or food, made only one mistake between them. One chimp said that sponges were food. But, it turns out, this chimp regularly gobbled up sponges that were used around his compound to soak up spilled soft drinks.

Because chimpanzees and humans share 98.5 per cent of their genetic makeup, the former's exploits may not be surprising. The other 1.5 per cent can look very large or very small. But lesser primates such as rhesus macaque monkeys can be taught to play video games, which they seem to enjoy doing more for the fun of it than for rewards of food. (They are also apparently competitive, doing better when seated next to another monkey.) They can also learn to choose the higher of two numbers, apply transitive properties to new pairings and select the higher of two abstract quantities represented by letters.

Deborah Blum shrewdly reminds us of such feats in the first two chapters of her new book on the controversies surrounding primate research. Here is the crux of the issue: these animals can communicate with us, reciprocate some kind of emotional attachment, ask us to tickle them, even beg us not to hurt them. Yet other humans (almost never the same ones who communicate with the primates) perform a variety of damaging experiments on them. The benefits of some, although not all, of these experiments - benefits to primates as well as humans - are beyond doubt. We moderns have a hard time seeing tragic dilemmas for what they are: conflicts between two sets of principles, situations in which there is no clear right answer. Participants in the animal-protection controversy who see no validity to the other side's views have chosen to blind themselves for political reasons, putting aside loyalty to the truth.

Through a series of extended glimpses inside the labs and minds of primatologists and a few others, Blum helps us to understand the zealots on both sides of the current controversy, yet she has also found some people capable of at least doubting their own positions. After defending the use of primates in disease research, the chief veterinarian at a large primate research centre admits: "And, yet, I don't feel so right about what I do that I could turn to an animal rights advocate, and say, you are wrong. In the end I think I'm probably wrong." In the heat of the

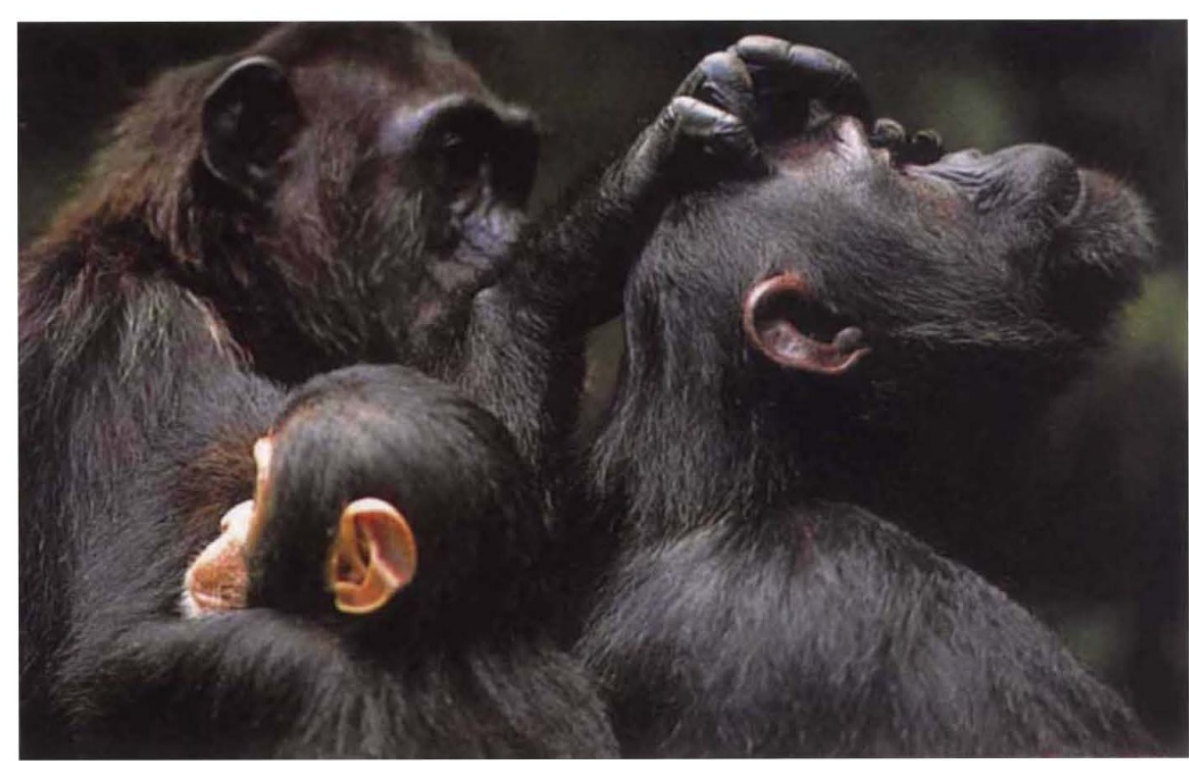

HEAD scratcher - picture from the cover of Chimpanzee Cultures edited by $\mathbf{R}$. $\mathbf{W}$. Wrangham et al.. It arose from a 1991 Chicago symposium entitled "Understanding Chimpanzees: Behavior and Diversity". Harvard University Press, \$39.95, £29.95.

clash, such humility has become rare. More often, those who became scientists to search for the truth end up learning that, for strategic reasons, the truth is secondary.

Active suppression, at least, is more the province of private companies than scientists. Perhaps the most egregious case resulted from a 1983 letter to the editor of the Journal of Medical Primatology from the head of the International Primate Protection League, criticizing a private company's proposal to study hepatitis in chimpanzees. The company sued, for $\$ 4$ million each, the journal, its editor, his university, the writer of the letter, another publication (New Scientist) that had run a piece about the proposal, the New Scientist writer and the distributors of both publications. All settled out of court except the journal's editor, who won after seven years and $\$ 2$ million in legal fees $(\$ 70,000$ from his own pocket). The National Association for Biomedical Research, at the forefront of the counter-attack against the animal-rights movement, even filed two briefs on the side of the company. Blum describes other cases in which any questioning of animal use in research is discouraged or punished.
The cute style and frequent metaphorical descriptions in The Monkey Wars betray its origin as a series of articles for the Sacramento Bee. But if it has certain analytical limits of journalism, the book represents high-quality journalism - rich details, smooth writing and general accuracy - for which Blum's articles won her a Pulitzer prize. Blum visited half-a-dozen primate research centres and interviewed at least four dozen people involved in the primate-research controversy, most of them active researchers.

Despite some meandering, The Monkey

Wars repeatedly returns to the important political issues involved in primate research, usually expressed by Blum's respondents. Beginning with vignettes meant to impress us with the similarities of apes and monkeys to humans, the author describes research on brain structure, stress, deafferentation, virology, organ transplants. Without taking sides, she gives us insights into the worldviews of researchers, animal protectionists and the veterinarians and managers of primate colonies or research centres, and especially the diversity within each group. Two chapters discuss the threat of infectious diseases transmitted from primates to humans, particularly those caused by viruses such as HIV that can sit quietly in other species but then rip through human populations, aided by the genetic proximity. Blum's argument is often submerged in the details, but her point is always clear. The final chapter, after describing a man responsible for 1,600 apes and monkeys who "faults animal activists for making the monkeys too human... scientists for making them too mechanical", crystallizes the essential dilemma of primate research, and warns against easy answers. 
This book will change no minds. But it may encourage us to listen to those with less strident and extreme positions, who know a real dilemma when they see it, who refuse easy choices. Among the human primates, at least, they are the main ones who have been voiceless in the controversy so far. An evolutionary virologist, dismayed by the viral risk of organ transplants from baboons to humans, says of a surgeon that he "may say that he sees no real ethical issues here.... But if you don't see them, then you're the wrong person to be making the decision. Maybe this is not an area to be decided by transplant surgeons at all."

\section{Coming plagues?}

\section{Robert Desowitz}

The Hot Zone. By Richard Preston. Random House/Doubleday: 1994. Pp. 336, $\$ 23, £ 14.99$.

POGO's seminal observation (for those of you who remember Pogo) that "we have met the enemy and they is us" could equally apply to viral biology as to human self-destructiveness. By its insinuation into the host's genome, the virus becomes, in the genetic sense, as much as the host as the host itself. Sometimes this splice of life is clinically quiescent; sometimes it causes an annoying but not life-threatening illness; sometimes it is fatal. And there are two viruses that are man's worst nightmare, Marburg and Ebola.

Marburg and Ebola, filoviruses related to the influenza virus, strike humans with an unparalleled swiftness and destructiveness. The fatality rate is high, especially for Ebola, which kills more than 90 per cent of infected people. The course of the disease is horrible, with the explosive invasion virtually lysing its victim. There is no known cure, and no vaccine or other prophylactic. The viruses are presumed to be zoonotic agents but the natural host, or hosts, remains unidentified. The mechanism(s) of transmission is imperfectly understood. These are viruses surrounded by mystery, the mystery being even more ominous because of the uneasy suspicion that they may have the potential to break out and become "Doomsday bugs".

Marburg and Ebola are, in the literary sense, highly 'photogenic' pathogens that have been awaiting their biographer. Richard Preston attempts to fulfil this role in The Hot Zone. He adopts the docudrama format to tell two stories: the people story and the monkey story. The people story begins with a French expatriate

The culprit - Ebola, one of the group of filoviruses and the cause of Ebola fever.

employee of a Kenyan sugar plantation who takes his African girlfriend on a weekend's holiday to Mount Elgon, where they visit Kitum cave. A week later he sickens, becomes progressively more ill and dies, haemorrhaging from all his bodily orifices. A doctor who attends him develops the same symptoms and dies. Blood is drawn and sent to the Centers for Disease Control in Atlanta, Georgia, where a diagnosis of Marburg virus is made. Seven years later, in 1987, a tenyear-old Danish boy visits his parents who work for a Kenyan relief organization. The family goes on an outing to Kitum cave and shortly afterwards the boy falls sick and dies. The US Army Medical Research Institute of Infectious Diseases, Maryland, takes a blood sample and discovers that it is positive for Marburg. The boy's parents and sister are unaffected, as was the Frenchman's girlfriend. An intensive study of Kitum cave and its flora and fauna fails to reveal the virus. Meanwhile, Africans in remote villages in Zaïre are dying of Ebola. Another intensive expedition is mounted but again fails to find Ebola's reservoir.

The monkey story, which makes up the longest segment of the book, describes a killing outbreak of infectious disease in monkeys held in a commercial facility in Reston, Virginia, about ten miles from Washington DC. These were crab-eating macaques imported from the Philippines. US Army virologists diagnose Ebola. But what is this African virus doing in Philippine monkeys and why isn't it killing the animal attendants who develop antibodies to the virus but remain asymptomatic? The US Army comes in and "nukes" the monkey house.

Preston's writing is rich in such 'army speak': the virus containment facility is the "hot zone"; the human containment facility is "the Slammer". The book is also rich in 'pseudo-science speak': the virus "jumps" and "expands to burn"; the replicating viruses are "blobs" and "fat bricks" bursting from their host cells; the "healthy monkeys went nuts". It is a style of writing that complements the drama of his story. It is also a style of writing that may make you cringe.

The real problem with this book is not Preston's writing style or his lack of adequate insights into viral biology. It is his superficiality and failure to address the immensely important issues that his story illuminates. Does he not get an uneasy feeling, as I do, that military organizations are the custodians of what is considered to be the most lethal pathogen of humans - a pathogen that with a bit of genetic tinkering could become the Andromeda strain? Is he not concerned that there were no contingency plans or laws to enable authorities to deal rapidly and effectively with a potential outbreak of a highly pathogenic agent? Or to prevent the agent from entering the United States in the first place? After the Reston monkey-house disaster the same company imported the same species of monkey from the same place with the same result - virtually all the monkeys died of an Ebola or Ebola-like viral infection. Why does he not ask why there is apparently so little research on so lethal an organism about which so little is known?

For all its shortcomings, this is a powerful book. It will scare the hell out of people. But to my mind the unattended issues of public health and research are almost as scary as the virus itself.

Robert Desowitz is in the Department of Protozoology, Prince Leopold Institute of Tropical Medicine, Nationalestraat 155, B2000 Antwerp, Belgium. From 15 January 1995 he will be in the Department of Tropical Medicine and Medical Microbiology, University of Hawaii, 3675 Kilauea Avenue, Honolulu, Hawaii 96816, USA. 